\title{
Effects of Authentic English-Language Videos on EFL Students' Speaking Anxiety
}

\author{
Hui Wen Lu, Jia-Ying Lee, and Ming Huei Lin
}

\begin{abstract}
Foreign language learning anxiety has been widely discussed over past decades, particularly the anxiety that students suffer when speaking. For most EFL students in Taiwan, for instance, speaking English is not a common occurrence in daily life, which results in their apprehensiveness when speaking English either in public or in class. Although previous studies have indicated possible variables leading to learners' speaking anxiety, little attention has been paid to examining what pedagogical instructions may effectively improve learner anxiety in speaking English, in particular in Taiwan. This being so, this study aims to explore the effects of learning through online, authentic video clips on Taiwanese EFL non-English-majors' performance on speaking anxiety. A total of 29 first-year college students joined the experimental study, which lasted for five weeks. Quantitative data were collected to shed light on the students' changes over the course of the experiment. The results reveal marginal significance in terms of the students' overall learning attitudes, with a particularly apparent improvement in their communication apprehension. Students' speaking skills were also significantly improved, lending further support to the effects of authentic English-language videos on EFL student speakers. This paper concludes with implications and suggestions for future research.
\end{abstract}

Index Terms-Foreign language speaking anxiety, speaking class, authentic contexts.

\section{INTRODUCTION}

Foreign language learning anxiety has been discussed for decades, especially the anxiety that students suffer in speaking classes. Many studies have shown that foreign language learning anxiety has a negative effect on the oral performances of foreign language learners [1]-[6]. Moreover, this anxiety has been identified as one of the main factors detrimental to the acquisition of foreign languages. In the era of globalization and internationalization, English has become the common language of communication and trade that connects people all over the world. Learning English is thus an essential subject for everyone in non-English speaking countries such as Taiwan. For students to whom English is a foreign/additional language, the primary way to communicate with people from different countries is speaking English. In most EFL contexts, the students speak

Manuscript received September 26, 2018; revised April 19, 2019. This work was supported in part by Taiwan's Ministry of Science and Technology under Grants MOST 104-2410-H-032-051 and MOST 107-2410-H-032-057.

The authors are with the Department of English, Tamkang University, Taiwan (corresponding author: M. H. Lin; e-mail: 144720@mail.tku.edu.tw, jylee@mail.tku.edu.tw,johnlinminghuei@gmail.com). and are exposed to English only in the English classroom. Horwitz, Horwitz, and Cope [7] noted that since speaking in the target language seems to be the most threatening aspect of foreign language learning, the current emphasis on the development of communicative competence poses particularly great difficulties for the anxious student. These researchers also developed the Foreign Language Classroom Anxiety Scale (FLCAS) to examine the situation-specific anxiety that learners experience in the foreign language-learning classroom and its impacts on language learning. For EFL students in Taiwan, most exposure to the target language also occurs in foreign language-learning classes. That is, students speak English mostly in their English classes and seldom use English in their daily life or in authentic contexts such as talking to foreigners in English [8].

For Taiwanese EFL students, speaking English is not a common phenomenon, and is especially avoided when they are not well prepared first or when they are not even ready to speak at all. This may be because they are afraid of making errors in any components of the language they are learning, such as pronunciation and grammar. Most students fear speaking English in public or volunteering to answer questions in class. In the EFL classroom, students suffer more anxiety in the conversation class than in other classes, such as the reading class.

The discussion highlights the importance of alleviating student speakers' anxiety. Indeed, it has been found that differences in foreign language anxiety levels affect one's performance. For example, a study by Liu [9] used a triangulated methodology (i.e., survey, observation, reflective journals and interviews) to systematically explore reticence and anxiety in oral English classroom-learning situations and in some underlying factors (e.g., personality, self-esteem, self-confidence, willingness to communicate, traits and personality). His findings confirm that different levels of speaking anxiety are reflected in different levels of language proficiency.

Previous studies have shown many variables contributing to students' anxiety. However, the extent to which speaking English in an authentic context (e.g., communicating with foreigners in English outside the language-learning classroom) may cause their anxiety has not been fully examined. This is the gap that this research aims to fill by means of answering the following two questions: (1) Does authentic communication with native speakers improve Taiwanese EFL non-English-majors' language anxiety in speaking English? (2) As a related question, did the participants improve their speaking abilities after the experiment? 


\section{LITERATURE REVIEW}

\section{A. Language Anxiety}

While Spielberger [10] defines anxiety as a "subjective feeling of tension, apprehension, nervousness, and worry associated with an arousal of the autonomic nervous system" (p. 15), the feeling of nervousness associated with language learning is generally known as language anxiety. In other words, language anxiety may be interpreted as one's concerns or negative emotional reaction towards learning or actually using a second/foreign language. According to Abu-Rabia [1], "the foreign language learner characterized as having anxiety is usually worried, physically insecure, and unable to engage in situational learning" (p. 712). There are specific characteristics of formal foreign language learning that have the potential to provoke anxiety in learners. For example, language learning anxiety has been attributed to the inability to present one's ideas and opinions very well in the target language, which can undermine self-esteem and threaten one's self-image [7]. In addition, the inability to pronounce words correctly or use correct grammar can lead to negative evaluation by others. Moreover, confusion and embarrassment may result from the inability to comprehend spoken and written input. These types of anxiety contribute to making formal foreign language learning a particularly unpleasant experience for many learners [11].

\section{B. Foreign Language Classroom Anxiety}

Many SL/FL English teachers and students think that anxiety from language learning will affect learners, but in 1986, Horwitz [12] noted that "the empirical literature does not substantiate a clear-cut relationship between anxiety and second language achievement or performance" (p. 559). Horwitz also comments that "existing measures of anxiety do not test an individual's response to the specific stimulus of language learning" (p. 559). Thus, Horwitz et al. [7] developed a scale called the Foreign Language Classroom Anxiety to assess language learners in universities. This scale has been widely adopted in many studies by many researchers [4], [6], [9], [13]-[17]. A 5-point Likert scale was used in this instrument, ranging from 5 "strongly agree" to 1 "strongly disagree." Thirty-three items were classified into three domains in this instrument, namely, communication apprehension, test anxiety and fear of negative evaluation.

First, communication apprehension is a reflection of shyness triggered by the negative feeling of anxiety when one communicates with others [7]. In this regard, communication apprehension as such may grow either strong or weak with individuals' levels of fear or anxiety associated with communication with others. Horwitz et al. [7] took a further step to use the construction of communication apprehension in their conceptualization of foreign language anxiety. The researchers see interpersonal interactions as the main emphasis in the English class. In a foreign/second-language classroom, language learners' speaking ability includes learning a second language and performing the language. Therefore, communication apprehension in a foreign language is a different context from this feeling in other contexts. There are two components in oral communication: listening and speaking. MacIntyre and Gardner [3] mention that oral communication with others can be rather anxiety-provoking in foreign language activities. Young [18] also finds that most language learners are particularly nervous when they are speaking a foreign language in class. The reason for such phenomena with foreign language learners may be the lack of control in oral communication [19].

Second, test anxiety is defined by Horwitz et al. [7], who state that test anxiety refers to students" "unrealistic demands on themselves... [they] feel that anything less than a perfect test performance is a failure" (p. 128). Thus, she also claimed that "students who are test-anxious in foreign language class probably experience considerable difficulties since tests and quizzes are frequent and even the brightest and most prepared students often make errors" (p. 128). As mentioned above, test anxiety is a type of performance anxiety derived from a fear of failure and evaluative situations. Although it overlaps with other constructs of foreign language anxiety, test anxiety is relevant to all academic contexts where performance evaluation is frequent [15].

Third, as Horwitz et al. [7] define it, "Fear of Negative Evaluation is defined as apprehension about others' evaluations, avoidance of evaluation situations, and the expectation that others would evaluate oneself negatively" (p. 128). They also state that students with such negative feelings may also be acutely sensitive to the evaluations real or imagined of their peers. In a foreign-language context, negative evaluation derives mainly from both teachers and follow-students, because foreign languages require continual evaluation by the teacher, and anxious students may also be intensely susceptible to the evaluations of their peers. Students with a fear of negative evaluation may adopt the action of avoidance.

\section{THE STUDY}

\section{A. Participants}

The participants in this research were 29 first-year non-English-majors who enrolled in an 18-week English speaking and listening course which primarily focused on speaking and listening training. The participants were recruited through convenience sampling from the researcher's classes. The English speaking and listening course ran two classes. One was from the Department of Economics, and the other was from Information Communication. On average, both classes comprised students aged between 18 and $20(M=18.8)$. All participants were attending a university in the northern part of Taiwan. The participants spoke Mandarin as their native language and learned English as a foreign language. These students had learned English in compulsory school education for at least 10 years. They had learned English from non-authentic language-learning resources such as English textbooks and magazines designed for English learning. Before the experiment, the participants had limited opportunities to speak English in authentic contexts or in their everyday life. After consenting to join the experiment, they were then involved in a five-week treatment. 


\section{B. Treatments}

The participants were offered materials of two types. The first was the original textbook ( $Q$ : Skills for Success, Listening and Speaking 2) assigned by the university. This book, having a total of 10 topics, is used for a whole academic year (36 weeks). To comply with the syllabus of the course, the experimental period allowed this research to cover two topics, "Do it yourself" and "Recycle."

To complement the textbook assigned and to expose students to authentic materials, online clips related to the topics mentioned above were also introduced to the participants. The clips used consisted of items such as news on TV or home-video recordings, rather than pre-produced movies, TV series or other productions. To collect suitable material, the researchers first filtered the video content to find videos related to the textbook topics that had been chosen for this experiment: "Do it yourself" and "Recycle." The videos chosen were then played and discussed during classes. Specifically, the chosen clip would be shown to the participants twice, which took about six to 10 minutes for each clip. The participants were then divided into groups where they were given 10 to 15 minutes to discuss its content. Next, they shared their thoughts and questions with other groups, which took about 15-20 minutes, depending on how much the students had to share. This step allowed them to practice using/speaking the authentic language they had just picked up from watching the clips. Afterwards, the participants were encouraged to search similar videos online for language to enhance their learning.

\section{Data Collection}

Questionnaire. To examine learners' anxiety, the FLCAS questionnaire [7] was adopted. The questionnaire consists of two sections: the participants' demographic information and the Foreign Language Classroom Anxiety Scale. The former elicited data including department, name, gender, age and certificates of English proficiency. The latter contained 33 items that evaluated learners' anxiety levels when attending language classes. FLCAS has been accepted as a reliable tool in the field for over three decades. It uses a 5-point Likert scale, ranging from 5 "strongly agree" to 1 "strongly disagree." Twenty-four statements are positively worded, and nine statements are negatively worded. For example, a positive statement is "I start to panic when I have to speak without preparation in language class," and, in contrast, a positively worded item is "I feel confident when I speak in foreign language class." According to Horwitz et al. [7], there are three underlying factors in the FLCAS: 1) communication apprehension, 2) test anxiety and 3) fear of negative evaluation. For example, Item 4 in the communication apprehension subscale is "It frightens me when I don't understand what the teacher is saying in the foreign language." Item 9 in the test anxiety subscale is "The more I study for an oral English test, the more confused I get," and Item 19 in the fear of negative evaluation subscale item is "I am afraid that my language teacher is ready to correct every mistake I make." Validity and reliability were ensured by previous researchers [4], [6] [9], [13]-[17], [20].

Speaking pre- and post-test tasks. To complement the results of the questionnaire, students' speaking abilities before and after the treatment were also evaluated. Each individual was asked to record themselves making conversation in English with a non-Chinese speaker on or off campus. No specific topics were assigned, but each conversation had to last at least one minute. The participants then directly sent their digital recording to two raters for assessment (described below).

Speaking assessment. To assess students' speaking abilities recorded in tapes, two raters were involved: one of the researchers and an experienced teacher who had also taught English to first-year college students for years at the same experimental site. Before the assessment, the raters had agreed on the features of the rubric adopted from the IELTS Speaking band descriptors (public version). In general, the rubric divides speakers into nine bands according to their speaking performance, with a score of one indicating the least proficiency in speaking and nine the greatest fluency and coherence in speaking. The two raters first performed the assessment separately and then came together for a discussion when they had assigned different scores to the same student speaker. After discussion, a single mark would be agreed on and assigned to the student.

\section{Data Analysis}

The data collected from the experimental study were analyzed using paired-sample $t$-tests. Specifically, the tests compared the differences in the mean scores of the FLCAS results before and after the treatments, indicating students' levels of speaking anxiety, and assessed students' speaking performance recorded in the video clips they made.

\section{RESUlts}

A paired-sample $t$-test was conducted to compare the levels of anxiety for students before and after the experiment. As Table I shows, after the experiment, the participants showed a marginally significant difference in the scores for the pre-test $(\mathrm{M}=2.79, \mathrm{SD}=.71)$ and the post-test $(\mathrm{M}=2.64$, $\mathrm{SD}=.60)$, at $t(28)=1.96, p=.06$. This suggests that the teaching approach used in this research can produce nearly significant improvement in students' learning attitudes to speaking.

TABLE I: PAIRED T-TESTS FOR THE OVERALL FLCAS

\begin{tabular}{lcccccc}
\hline \hline & $\mathrm{N}$ & Mean & $\mathrm{SD}$ & $t$ & $d f$ & $p$ \\
\hline Pre-test & 29 & 2.79 & .71 & & & \\
\cline { 2 - 4 } Post-test & 29 & 2.64 & .60 & & & .96 \\
\hline \hline
\end{tabular}

Table II shows the results of descriptive statistics for average subscales for the FLCAS. First, in terms of communication apprehension, there was a statistically significant difference between the pre-test $(M=2.90, \mathrm{SD}$ $=.73)$ and the post-test $(M=2.71, \mathrm{SD}=.71)$, at $t(28)=2.03$, $p=.05$. This means that after the experiment, the participants made significant improvement in communication apprehension. However, in terms of both test anxiety and fear of negative evaluation, no significant differences were found $(t(28)=1.23, p=.23 ; t(28)=1.46, p=.16$, respectively $)$. 
Clearly, even though after the experiment the participants seemed to feel less anxious in these two subscales, such changes failed to reach significant levels.

TABLE II: PAIRED T-TESTS FOR THE FLCAS SUBSCALES

\begin{tabular}{llllllll}
\hline \hline Subscales & Tests & $\mathrm{N}$ & $\mathrm{M}$ & $\mathrm{SD}$ & $t$ & $d f$ & $p$ \\
\hline Communication & Pre & 29 & 2.90 & .73 & \multirow{2}{*}{2.03} & \multirow{2}{*}{28} & \multirow{2}{*}{.05} \\
\cline { 2 - 6 } Apprehension & Post & 29 & 2.71 & .71 & & & \\
\hline \multirow{2}{*}{ Test Anxiety } & Pre & 29 & 2.68 & .72 & \multirow{2}{*}{1.23} & \multirow{2}{*}{28} & \multirow{2}{*}{.23} \\
\cline { 2 - 6 } & Post & 29 & 2.57 & .53 & & & \\
\hline $\begin{array}{l}\text { Fear of Negative } \\
\text { Evaluation }\end{array}$ & Pre & 29 & 2.76 & .81 & \multirow{2}{*}{1.46} & \multirow{2}{*}{28} & \multirow{2}{*}{.16} \\
\cline { 2 - 5 } & Post & 29 & 2.60 & .76 & & & \\
\hline \hline
\end{tabular}

Table III shows that, after the experiment, students' actual performance in speaking with an English-speaking international student was statistically significantly improved $(t(28)=-5.48, p=.000)$. This suggests that the pedagogical practice used in this study had an effect on helping students to develop their speaking abilities.

TABLE III: PAIRED T-TESTS FOR STUdENTS' SPEAKING PERFORMANCE IN PRE- AND POST-TEST VIDEOS

\begin{tabular}{lllllll}
\hline \hline Video & $\mathrm{N}$ & $\mathrm{M}$ & $\mathrm{SD}$ & $t$ & $d f$ & $p$ \\
\hline Pre-test & 29 & 2.62 & .49 & & & \\
\cline { 2 - 5 } Post-test & 29 & 3.14 & .52 & & & \\
\hline \hline
\end{tabular}

\section{DISCUSSION}

This section draws conclusions from the results to answer the two research questions listed above and to present the pedagogical implications, limitations of the study and recommendations for further study.

\section{A. Regarding Research Question 1}

The first goal of the present study is to investigate students' speaking anxiety when learning a foreign language. This was done by involving students in video-aided speaking instruction and video-recording tasks, in the hope of alleviating students' level of anxiety when speaking English. The results show that, in general, most of the participants felt less anxious after the experimental treatments; Table 4.2 above indicates a marginal significant difference. A closer look at the results for each underlying factor, however, reveals that only "communication apprehension" was improved. No significant gain was found in either test anxiety or fear of negative evaluation. These mixed findings merit further discussion.

First, it is important to discuss possible reasons why the experimental treatment brought about positive effects on eliminating participants' speaking anxiety. As is commonly acknowledged, communication apprehension refers to the anxiety resulting from the interaction and communication between people. Such apprehension might have thus been reduced after the participating students grew more familiar with speaking English to one or more English-speaking foreigners. Another possibility may be that the constant input of watching online clips in English might have also created sufficient language input for students, thereby resulting in observable output (i.e., actually speaking English). While all these factors are probable, it is also important to address possible causes for non-experimental effects on student speakers in terms of test anxiety and fear of negative evaluation. One reason for this can be found in the study by MacIntyre and Gardner [21]. As these researchers stated, speaking-in-class anxiety and peer evaluation are some elements of foreign language classroom anxiety, but they do not affect test anxiety. Test anxiety may be a general problem, non-specific to the language classroom [17]. Additionally, fear of negative evaluation is also considered to be a relatively enduring personality trait [17]. In other words, it is difficult for outward treatments such as those in this study to affect such a quality. Nevertheless, this is not to say that treatments are of no use at all in helping students overcome their anxiety when faced with their fear of tests and negative evaluation, because this study's results may all be attributed to the fact that a six-week experiment was too short to bring about sufficient impact on such individual characteristics. This is, of course, an issue requiring examination in a longitudinal experiment.

\section{B. Regarding Research Question 2}

To reveal the degree of improvement in speaking ability for Taiwanese EFL non-English-major students after the experiment, the teacher-researcher and the rater examined their speaking performances by marking their videos based on the IELT Speaking band descriptors. The results show statistical significance difference for the performance before and after the treatments. This suggests that the experiment did help enhance student speaking ability. In particular, the study results suggest that interviewing a foreigner in English as an assignment, along with in-class speaking activities, not only alleviates students' anxiety but increases their speaking ability. Both quantitative and qualitative findings show improvements in students' proficiency in spoken English. Qualitatively, in their pre-test videos, most students appeared embarrassed and nervous when they first videotaped themselves speaking English with English speakers. Moreover, in their conversation, they often used simple sentences, isolated words and left long pauses. In the first round of video recording, the students talked less than their foreign partner(s) and sometimes failed to create follow-up responses after their foreign partner had answered the questions they asked. Such quietness might have been caused by their education background, since most Taiwanese students did not have or rarely had the chance to learn English-speaking skills when they were in elementary or high school. In other words, they had had little opportunity to use English to communicate in speech with others. However, after 5-week experimental treatments where they were given more opportunities to listen to English and speak it, they improved their use of English in communicating and interacting with others. As shown in the post-test, when students did the same video assignment as for the pre-test, even though some still showed embarrassment and looked nervous, in general, they were more talkative than before. Additionally, more students had more interaction than before when they talked with a foreign partner. The improvement was also noticed in the increase of video length. More students were able to create a longer conversation in their 
post-test task. This is because, as shown in their videos, they now offered more responses in their conversations and even asked more spontaneous questions, which is evidenced by the many follow-up questions that were not kept in their notes. This observation is based on the fact that they read less or even took notes when asking follow-up questions, but did not do either in the pre-test video task. On the one hand, these findings echo those of Chan and $\mathrm{Wu}$ [15]. When English learners talked to native English speakers more frequently, they felt less anxious. On the other hand, such interpretation is also consistent with that of Liu [9], who stated that the more proficient in English students are, the less anxious they are in oral English class. In other words, when students improve their level of English, their speaking anxiety is dispelled. Consequently, an English teacher should encourage English learners to speak English in authentic contexts more frequently, to enhance their English proficiency.

\section{LiMITATIONS AND SUGGESTIONS FOR FUTURE STUDIES}

While the experimental design was itself valid, the experiment opens up a few research opportunities for future scholars to consider. First, the experiment recruited only participants from northern Taiwan. Therefore, they might not be representative of the greater population of college EFL students in Taiwan. The researchers of this study suggest that further studies may recruit participants from different areas or even students at various levels of English or different majors. Second, there were 86 participants in this research at the beginning, but only 29 participants entered into the main analysis of the study. This is because many students failed to comply with the requirement to upload their videotaping tasks before the deadline, although the teacher frequently reminded them. Hence, future researchers may consider different means of collecting sufficient videos for such experiments. In addition, due to the participants needing to videotape themselves with a foreigner in English in this research, the participants spent too much time finding a foreigner who was suitable and willing to be taped. Therefore, for future studies, researchers may consider finding suitable foreigners for their students first. This may increase students' willingness to complete such a task and hand in their videos as required. Furthermore, most of the participants' spoken English ability in this study was probably not sufficient to allow them to perform the task easily, as required here. Replication of the experiment with learners of advanced English ability may be helpful in shedding light on the extent to which these findings may be generalized to other EFL students.

\section{CONCLUSION}

To help students become more active and feel less anxious when speaking English, English teachers may ask students to speak English in authentic contexts more frequently, as was done in this experiment. They need not only to practice English in the classroom with classmates or a teacher but also to be familiar with using English in real life. In the university,
English classes should be more student-centered [22] and more practical for students. Interviewing a foreigner in English as an assignment for students would help them speak English in an authentic context. According to the findings of this research, interviewing a foreigner is a positive influence on students' speaking performance and language learning anxiety.

\section{REFERENCES}

[1] S. Abu-Rabia, "Teachers' role, learners' gender differences, and FL anxiety among seventh-grade students studying English as a FL," Educational Psychology, vol. 24, no. 5, pp. 711-721, 2004.

[2] T. Gregersen and E. K.Horwitz, "Language learning and perfectionism: Anxious and non-anxious language learners' reactions to their own oral performance," The Modern Language Journal, vol. 86, no. 4, pp. 562-570, 2002.

[3] P. D. MacIntyre and R. C. Gardner, "Language anxiety: Its relationship to other anxieties and to processing in native and second languages," Language learning, vol. 41, no. 4, pp. 513-534, 1991.

[4] S. Matsuda and P. Gobel, "Anxiety and predictors of performance in the foreign language classroom," System, vol. 32, no. 1, pp. 21-36, 2004.

[5] E. M. Phillips, "The effects of language anxiety on students' oral test performance and attitudes," The Modern Language Journal, vol. 76, no. 1, pp. 14-26, 1992

[6] D. J. Young, Affect in Foreign Language and Second Language Learning: A Practical Guide to Creating a Low-anxiety Classroom Atmosphere, Boston: McGraw-Hill College, 1998.

[7] E. K. Horwitz, M. B. Horwitz, and J. Cope, "Foreign language classroom anxiety," The Modern Language Journal, vol. 70, no. 2, pp. 125-132, 1986.

[8] S. C. Baker and P. D. MacIntyre, "The role of gender and immersion in communication and second language orientations," Language Learning, vol. 50, no. 2, pp. 311-341, 2000 .

[9] M. Liu, "Anxiety in Chinese EFL students at different proficiency levels," System, vol. 34, no. 3, pp. 301-316, 2006.

[10] C. D. Spielberger, "Manual for the state-trait anxiety inventory STAI (form Y) (self-evaluation questionnaire)," 1983.

[11] E. K. Horwitz and D. J. Young, Language Anxiety: From Theory and Research to Classroom Implications, Pearson College Div, 1991.

[12] E. K. Horwitz, "Reflections on Horwitz (1986), preliminary evidence for the validity and reliability of a foreign language anxiety scale," TESOL Quarterly, vol. 50, no. 4, pp. 932-935, 2016.

[13] M. Azher, M. Anwar, and A. Naz, "An investigation of foreign language classroom anxiety and its relationship with students' achievement," Journal of College Teaching and Learning, vol. 7, no. 11, pp. 33-40, 2010.

[14] N. D. Baharum and K. Ariffin, “Anxiety in learning English among low achievers: The questions of gender, language preference and academic performance," in Proc. the International Conference on Science, Technology and Social Sciences (ICSTSS) 2012, pp. 299-308, 2014.

[15] D. Y. C. Chan and G. C. Wu, "A study of foreign language anxiety of EFL elementary school students in Taipei County," Journal of National Taipei Teachers College, vol. 17, no. 2, pp. 287-320, 2004.

[16] Y. N. Chiang, "Foreign language anxiety in Taiwanese student interpreters.," Meta,: Journal des traducteursMeta:/Translators' Journal, vol. 54, no. 3, pp. 605-621, 2009.

[17] B. Mak, "An exploration of speaking-in-class anxiety with Chinese ESL learners," System, vol. 39, no. 2, pp. 202-214, 2011.

[18] D. J. Young, "The relationship between anxiety and foreign language oral proficiency ratings," Foreign Language Annals, vol. 19, no. 5, pp 439-445, 1986.

[19] P. D. MacIntyre and R. C. Gardner, "Methods and results in the study of anxiety and language learning: A review of the literature," Language Learning, vol. 41, no. 1, pp. 85-117, 1991b.

[20] K. Yaikhong and S. Usaha, "A measure of EFL public speaking class anxiety: Scale development and preliminary validation and reliability," English Language Teaching, vol. 5, no. 12, pp. 23-35, 2012.

[21] P. D. MacIntyre, and R. C. Gardner, "Anxiety and second-language learning: Toward a theoretical clarification," Language Learning, vol. 39, no. 2, pp. 251-275, 1989.

[22] M. Koçak, "A novice teacher's action research on EFL learners' speaking anxiety," Procedia-Social and Behavioral Sciences, vol. 3, pp. 138-143, 2010. 


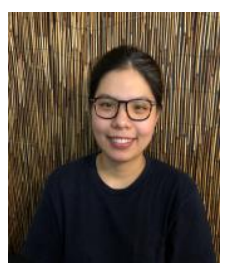

H. W. Lu completed the BA in English and MA in TESOL from Tamkang University. Her research interests include educational technology, speaking and listening skills, and learner attitudes. She has several years' teaching experience in higher education in related areas.

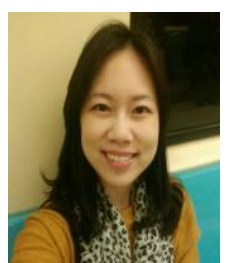

J.-Y. Lee received the degree of $\mathrm{PhD}$ from the University of Iowa. She is an assistant professor in the English Department at Tamkang University, Taiwan. She has wide-ranging interests in TESOL and applied linguistics.
M. H. Lin received his $\mathrm{PhD}$ degree from the University of Birmingham UK in 2012. He is now an associate professor in the English Department at Tamkang University, Taiwan. $\mathrm{He}$ is interested in computer assisted language learning and corpus-aided language learning. 